3. Murray N. The importance of dose and dose-intensity in lung cancer chemotherapy. Sem Oncol 1987, 14, Suppl 4, $20-28$.

4. Wong GG, Witek JAS, Temple PA, et al. GM-CSF: molecular cloning and purification of the natural and recombinant proteins. Science 1985, 228, 810

5. Nagata S, Tsuchiya M, Asano S, et al. Molecular cloning and expression of c-DNA for human granulocyte colony-stimulating factor. Nature 1986, 319, 415-418.

6. Laver J, Moore MAS. Clinical use of recombinant human hemopoietic growth factors. F Natl Cancer Inst 1989, 81, 1370-1382.

7. Pistoia V, Zupo S, Corcione A, et al. Production of colonystimulating activity by human natural killer cells: Analysis of the conditions that influence the release and detection of colony stimulating activity. Blood 1989, 74, 156.

8. Welte $\mathrm{K}$, Platzer E, Lu L, et al. Purification and biochemical characterization of human pluripotent colony-stimulating factor. Proc Natl Acad Sci USA 1985, 82, 126.

9. Pistoia V, Ghio R, Nocera A, et al. Large granular lymphocytes have a promoting activity on human peripheral blood erythroid burst forming units. Blood 1985, 65, 464.

10. Wing EJ, Magee DM, Whiteside TL, et al. Recombinant human granulocyte/macrophage colony stimulating factor enhances monocyte cytotoxicity and secretion of tumour necrosis factor $\alpha$ and interferon in cancer patient. Blood 1989, 73, 643-646.

11. Morrissey PJ, Bressler L, Charrier K, et al. Response of resident murine peritoneal macrophage to in vivo administration of granulocyte-macrophage colony-stimulating factor. $f$ Immunol 1988, 140, 1910-1915.

12. Sipe JD. Molecular biology of interleukin 1 and acute phase response. Adv Intern Med 1989, 34, 1-20.

13. Starnes HS Jr, Warren RS, Jeevanadam $M$, et al. Tumor necrosis factor and acute metabolic response to tissue injury in men. $\mathcal{F}$ Clin Invest 1988, 82, 1321-1325.

14. Klimo P, Connors JM, MACOP-B Chemotherapy for the treatment of diffuse large cell lymphoma. Ann Intern Med 1985, 102, 596.

15. Goldie JH, Coldman AJ. The genetic origin of drug resistance in neoplasms: implications for systemic therapy. Cancer Res 1984, 44, 3643.

16. Bronchud $\mathrm{MH}$, Howell A, Crowther D, et al. The use of granulocyte colony-stimulating factor to increase the intensity of treatment with doxorubicin in patients with advanced breast cancer and ovarian cancer. Brf Cancer 1989, 60, 121-125.

17. Rifkin R, Hersh E, Salmon S. Continuous intravenous administration of recombinant human granulocyte-macrophage colonystimulating factor is superior to i.v. bolus administration: a phase $I$ study. Proc Am Soc Clin Oncol 1988, 7, 165, 638.

18. Socinski MA, Cammistra SA, Elias, et al. Granulocyte-macrophage colony stimulating factor expands the circulating hemopoietic progenitor cell compartment in man. Lancet 1988, i, 1194-1198.

\title{
Diagnostic and Treatment Procedures Induced by Cervical Cancer Screening
}

\author{
Marjolein van Ballegooijen, Marc A. Koopmanschap, Gerrit J. van \\ Oortmarssen, J. Dik F. Habbema, Koos Th. N. Lubbe \\ and Heleen M.A. van Agt
}

The amount of diagnostic and treatment procedures induced by cervical cancer screening has been assessed prospectively and related to mortality reduction. Assumptions are based on data from Dutch screening programmes and on a scenario for future developments. With 5 invitations for screening, between ages 37-70 every eight years, 13 deaths are avoided per million women per screening year. Each death avoided is balanced by 2800 preventive smears, 9 women referred to a gynaecology department and 4 minor treatment procedures (conserving treatment or exconisation). 25 invitations in a life-time avoids 27 deaths per million women per screening year but with 7300 preventive smears, 22 referrals and 8 small treatment procedures. Thus intensifying screening will not only result in diminishing returns of extra screening efforts, but also in increasing risk for women to undergo unnecessary (no invasive disease or death avoided) diagnostic and treatment procedures. The balance between beneficial and adverse effects deteriorates strongly when hysterectomies play an important part in the management of cervical intraepithelial neoplasia.

Eur $\mathcal{F}$ Cancer, Vol. 26, No. 9, pp. 941-945, 1990.

\section{INTRODUCTION}

THE APPROPRIATENESS of screening for cervical cancer should be balanced between beneficial health effects and adverse effects and costs. As the avoidance of death is the principal aim, most evaluations have concentrated on the relation between life-years

Correspondence to $M$. van Ballegooijen.

The authors are at the Department of Public Health and Social Medicine, Erasmus University Rotterdam, P.O. Box 1738, 3000 DR Rotterdam, The Netherlands. saved and costs, which shows a diminishing return for the extra efforts involved in screening women more frequently [1-3]. Although unnecessary referrals and diagnostic and local therapeutic procedures are often discussed as the major adverse effect of cervical cancer screening, reports on this effect are scarce. Treatments of advanced cancer will be reduced by early detection. But due to follow-up of false positive smears and of lesions that would have regressed spontaneously, there will be a considerable increase in the number of diagnostic and minor therapeutic procedures. We have assessed this increase and related it to the number of life-years gained. 


\section{METHODS}

Yield of early detection

The effects of cervical cancer screening have been predicted by a mathematical model [4-6]. The model has been validated by analysing cervical cancer screening data from the British Columbia Cohort Study [7] and from pilot cervical cancer screening projects (1976-1985) in the Netherlands [8]. Both analyses led to similar conclusions [4]. Model-based analysis of the Dutch data led to the following estimates: (a) mean duration of the pre-clinical stages, 17 years and shortest at old ages; (b) regression rate of pre-invasive disease, $60 \%$ on average and highest at young ages; and (c) sensitivity of cervical cytology, $70 \%$ for cervical intraepithelial neoplasic (CIN) III.

With other assumptions (e.g. shorter duration, less regression or higher sensitivity) the observed Dutch screening results and incidence and mortality data could not be explained. The false positive rate, defined as the percentage of women in whom no CIN III or invasive cancer was found after an abnormal (at least moderate dysplasia) cervical smear, was $0.4 \%$. This number has been used in our calculations.

The validated model was used to simulate different screening policies in Dutch women during 1988-2015. Effects of screening occurring after 2015 have been taken into account. The population dynamics including deaths by causes other than cervical cancer have been incorporated into the model. The impact of cervical cancer screening before 1988 and of hysterectomies performed for reasons other than cervical cancer have also been taken into account. The population attendance rate has been assumed to be $65 \%$ on average, as observed in the Dutch pilot regions. Attendance decreases gradually for women over 50, to $55 \%$ for women aged 70 .

The model predicts the yearly number of smears, the yearly number of women diagnosed with CIN III, micro-invasive or cervical cancer by stage, the yearly number of women detected in whom no CIN III or worse is found during follow-up and the yearly number of women dying from cervical cancer.

Effects were calculated compared with no early detection, which was also simulated and in which women are only detected by symptoms. In our model detection by symptoms occurs in stage IB at the earliest.

\section{Diagnosis and treatment}

Assessment of the number of women referred to a gynaecological department because of an abnormal cervical smear is of major importance when estimating the extent of diagnosis induced by screening. Referred women are supposed to undergo colposcopy at least once; most will have ectocervical biopsy and in some endocervical curettage will be done. We calculated the number of referred women from the predicted numbers of detected women. We assumed that all women with a histologically confirmed CIN III + and $65 \%$ of the women followed up without a confirmed CIN III + have been referred to a gynaecologist. The other $35 \%$ of the latter group is assumed to have had only repeat smears done by the general practitioner, as the data from the pilot regions indicate. In the pilot regions, a Pap-smear with moderate dysplasia was followed by a repeat smear within a few weeks. A smear with severe dysplasia or more led to immediate referral to a gynaecologist.

To calculate the numbers of primary treatment procedures, a schcdulc has been devised with a realistic frequency of treatments by stage of disease. This schedule was applied on the predicted numbers of detected women by stage.

The possible treatment procedures in CIN and microinvasive
Table 1. Primary treatment procedures found (a) in eight Dutch hospitals ${ }^{\star}$ in 1982-1986 and (b) in pilot region of Nijmegen in 1981-1984

\begin{tabular}{|c|c|c|c|c|c|c|}
\hline \multirow[b]{2}{*}{ Treatment } & \multicolumn{2}{|c|}{$<\mathrm{CIN}$ III $\dagger$} & \multicolumn{2}{|c|}{ CIN III } & \multicolumn{2}{|c|}{ CIN IA } \\
\hline & (a) & (b) & (a) & (b) & (a) & (b) \\
\hline None & ND & $61 \%$ & - & - & - & 一 \\
\hline Conserving & ND & $10 \%$ & $25 \%$ & $28 \%$ & - & 一 \\
\hline Exconisation & ND & $6 \%$ & $64 \%$ & $15 \%$ & $38 \%$ & $0 \%$ \\
\hline $\begin{array}{l}\text { Exconisation }+ \\
\text { hysterectomy }\end{array}$ & ND & - & $4 \%$ & - & $46 \%$ & $50 \%$ \\
\hline Hysterectomy & ND & $23 \%$ & $7 \%$ & $48 \%$ & $16 \%$ & $50 \%$ \\
\hline Unknown & ND & - & - & $9 \%$ & - & - \\
\hline Total no. & & 66 & 663 & 46 & 24 & 2 \\
\hline
\end{tabular}

*Academisch Medisch Centrum (Amsterdam), Medisch Centrum Alkmaar, Sint Franciscus Gasthuis Rotterdam, Ziekenhuis Leyenburg (Den Haag), Ikazia Ziekenhuis Rotterdam, RK Ziekenhuis Groningen, Catherina Ziekenhuis Eindhoven and Westeinde Ziekenhuis Den Haag. tWomen referred to gynaecology department for cervical cancer assessment, in whom no CIN or only CIN I/II was found.

$\mathrm{ND}=$ no data .

cervical cancer are summarised in Table 1. Conserving treatments (cryocoagulation, electrocoagulation, laser-evaporation and diathermic ablation) and exconisations are considered as minor treatment procedures. Table 1 also shows the treatment procedures used in eight Dutch hospitals of different size and in different regions during 1982-1986 and in the screening programme in the pilot region of Nijmegen during 1981-1984 (office of Evaluation and Registration of Cervical Cancer).

The difference between the two data sets stresses the variability in medical practice. Hysterectomies were more frequent in Nijmegen. The reasons for this were not investigated. Current developments towards less aggressive treatments are the further introduction of colposcopy in the assessment of suspected cervical abnormalities and the decreasing rates for hysterectomies in general (there has been a more than $30 \%$ fall in the age group 35-50 in the Netherlands since the late 1970s [9]). Hospital departments that reported data on their treatment procedures are probably departments that follow these developments more closely than average. The percentage for less aggressive procedures in these hospitals, however, may be a good approximation for future practice. So we used the hospital data for the assumptions on the average stage-specific treatment (Table 2).

As no detailed data were available on treatment procedures in women with less than CIN III we based our assumptions for this group on reported information and on interviews with expert gynaecologists. Of the women followed up in whom no CIN III or invasive disease is found, $70 \%$ are women without any neoplasia and $30 \%$ are women with CIN I/II (Office of Evaluation and Registration of Cervical Cancer and ref. 10). We assumed no treatment in the first group. The percentages for conserving treatment and exconisations in the group with CIN I or CIN II are based on the assumption that about $60 \%$ of these women are treated and $40 \%$ are strictly followed up by cytology. From the treated group 30\% must (at least) have exconisation because in about $30 \%$ of the women with CIN the transformation zone and/or the lesion cannot entirely be seen with colposcopy. So the percentage of conserving treatments in the women referred with less than CIN III is assumed to be $13 \%(30 \% \times$ 
Table 2. Assumptions used in prospective calculation of numbers of primary treatment procedures: percentages of primary treatment procedures by cervical cancer stage

\begin{tabular}{|c|c|c|c|c|c|c|}
\hline \multirow[b]{2}{*}{ Treatment } & \multicolumn{2}{|c|}{$<$ CIN CIN } & \multirow[t]{2}{*}{ IA } & \multirow[t]{2}{*}{ IB } & \multirow{2}{*}{$\begin{array}{c}\text { Il }+ \text { (by } \\
\text { screening) }\end{array}$} & \multirow{2}{*}{$\begin{array}{c}\mathrm{II}+(\mathrm{by} \\
\text { symptoms }\end{array}$} \\
\hline & III $^{\star}$ & III & & & & \\
\hline $\begin{array}{l}\text { None (absence of CIN } \\
\text { III) }\end{array}$ & $81 \%$ & - & - & - & - & - \\
\hline Conserving & $12 \%$ & $24 \%$ & - & - & - & - \\
\hline $\begin{array}{l}\text { Conserving }+ \\
\text { exconisation } \dagger\end{array}$ & $1 \%$ & $1 \%$ & - & - & - & - \\
\hline Exconisation & $6 \%$ & $64 \%$ & $38 \%$ & - & - & - \\
\hline $\begin{array}{l}\text { Exconisation + } \\
\text { hysterectomy }\end{array}$ & - & $3 \%$ & $62 \%$ & - & - & - \\
\hline Hysterectomy & - & $8 \%$ & $0 \%$ & $90 \%$ & $40 \%$ & $16 \%$ \\
\hline Primary radiation & - & - & - & $10 \%$ & $60 \%$ & $79 \%$ \\
\hline $\begin{array}{l}\text { No primary treatment } \\
\text { (advanced disease) }\end{array}$ & - & - & - & - & - & $5 \%$ \\
\hline
\end{tabular}

*Women referred to a gynaecology department for cervical cancer assessment, in whom no CIN or only CIN I/II is found.

$\nmid$ Because of exconisations as re-treatment procedure assumed in $5 \%$ of women who had conserving treatment.

$60 \% \times 70 \%)$ and the percentage of exconisations to be $6 \%(30 \%$ $\times 60 \% \times 30 \%$ [rounded]). Moreover, $5 \%$ of the women who had conserving treatment are assumed to have exconisation as re-treatment.

In the management of women with cervical cancer stage IA, at least an exconisation is assumed. In the Netherlands there is a consensus to avoid diagnosing stage IA without doing exconisation first. The two possible primary treatment procedures in invasive cervical cancer stages IB or higher are radical surgery (with or without additional radiotherapy) and radiotherapy (alone). Data were studied from the eight hospitals, the Nijmegen region and from several other Dutch studies [11, 12]. All results were similar, and since no changes are expected in the near future, they were adopted. The difference in Table 2 in the assumptions between stage II + detected by early detection and stage II + detected by symptoms is based on the more favourable distribution over the stages IIA, IIB, III and IV in women detected by screening compared with those detected by symptoms [13]

\section{Screening policies}

We will discuss the results for three screening policies, with an increasing number of invitations for screening during a lifetime: 5, 10 and 25. More invitations implies a shorter interval berween successive invitations. These intervals are 8,5 and 2 years. The age-ranges are, respectively, 37-70, 27-72 and 26-74 years. This is a broad age range that does not correspond with most current practice. All three are so-called efficient screening policies. Policies are efficient when their distribution of screenings over the ages leads to the largest number of life-years gained at a certain level of costs, or conversely to the least costs for a certain number of life-years gained. Our study on the costs of cervical cancer screening is presented elsewhere [5].

\section{RESULTS}

The stage distribution, number of smears, number of women followed up and mortality from cervical cancer are shown in
Table 3. Outcomes of three efficient cervical cancer early detection strategies per year per million women (prospective calculations)

\begin{tabular}{lrrrrr}
\hline & \multicolumn{3}{c}{ No. of invitations } & No early \\
\cline { 2 - 4 } & 5 & 10 & 25 & \\
\hline C CIN III $\dagger$ & 140 & 299 & 745 & 0 \\
CIN III & 53 & 113 & 174 & 0 \\
IA & 5 & 6 & 5 & 0 \\
IB & 49 & 42 & 36 & 57 \\
II + scr & 1 & 1 & 1 & 0 \\
II+sympt & 101 & 92 & 82 & 124 \\
Total & 349 & 554 & 1044 & 182 \\
No. of smears & 36800 & 78700 & 196100 & 0 \\
Deaths from cervical & 67 & 60 & 54 & 80 \\
$\quad$ cancer & $(-13) \ddagger$ & $(-20)$ & $(-27)$ & \\
Life-years lost & 1172 & 989 & 854 & 1434 \\
& $(-262)$ & $(-446)$ & $(-580)$ & \\
\hline
\end{tabular}

^Per woman during her lifetime.

tWomen with abnormal smears in whom no CIN or only CIN I/II is found.

$\ddagger$ Difference compared with no early detection.

Table 3 for the three detection strategies. All results are presented per screening year, which means that the total outcomes and effects of screening in 1988-2015 have been divided by the number of screening years: 27 (i.e. "by year").

With more intensive screening a shift occurs in the detected precancers and cancers towards earlier stages. The total number of women followed-up increases significantly: from 349 (5 invitations) to 1044 ( 25 invitations) per million women per year, mainly due to the increase in follow-up of women with no histological abnormalities or only CIN I or CIN II. With intensification of screening from 5 to 10 invitations, 184 additional life-years are gained, while a further increase from 10 to 25 invitations adds only 134 life-years more per million women per year.

Intensifying the policy from 5 to 25 invitations per life-time causes a five-fold increase in the number of women referred (Table 4). This induces additional diagnostic and treatment procedures. More specifically, an increase from 5 to 25 invi-

Table 4. Effect on diagnostic and primary treatment procedures of three efficient cervical cancer early detection strategies (prospective calculations)

\begin{tabular}{lrrrr}
\hline & \multicolumn{2}{c}{ No. of invitations } & $\begin{array}{r}\text { No early } \\
\text { detection }\end{array}$ \\
\cline { 2 - 4 } & 5 & 10 & 25 & \\
\hline Women referred & $+117+$ & +266 & +598 & 182 \\
Conserving treatments & +25 & +53 & +106 & 0 \\
Exconisations & +47 & +96 & +157 & 0 \\
Hysterectomies & -2 & -2 & -3 & 72 \\
Primary radiotherapies & -19 & -26 & -35 & 104 \\
Total & +52 & +121 & +226 & 175 \\
\hline
\end{tabular}

$\star$ Per woman during her life-time.

+Per year per million women (all ages), difference compared with no screening. 
$+-+=$ preventive smears, $\Delta---\Delta=$ detected women,

$0--o=$ referred women, $+\cdots+\cdots=$ conserving treatment procedures induced $\Delta--\Delta=$ exconisations induced, $\bullet-\cdots$ hysterectomies avoided,

$+--+=$ radiotheropies ovoided and $\leadsto \Delta=$ decth from cervical cancer avoided.

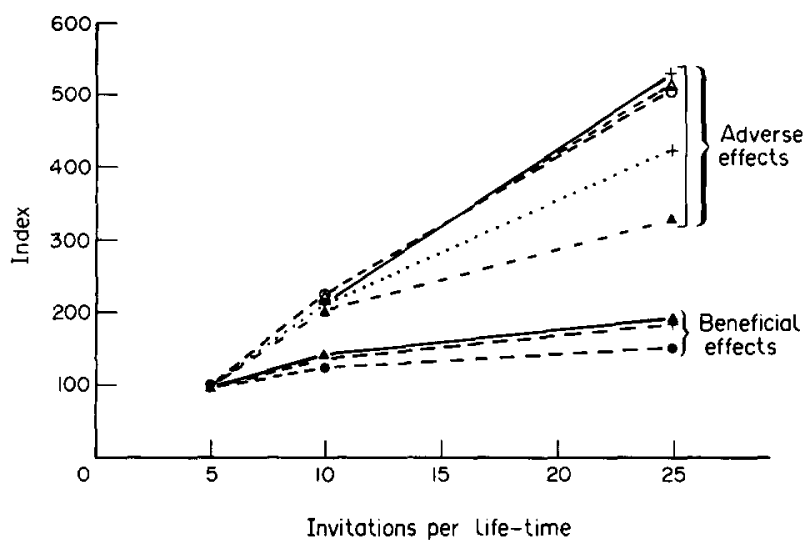

Fig. 1. Relationship between various beneficial and adverse effects of screening and intensity of screening, as represented by efficient cervical screening policies with 5,10 and 25 invitations. Level of effects at 5 invitations is set to 100 (all lines go through origin).

tations makes the number of conserving treatments rise from 25 to 106 and exconisations rise from 47 to 157 per million women per year.

The effect on the number of hysterectomies (total plus radical) of intensifying early detection efforts is modest. The reason is that the rise in the number of total hysterectomies caused by the increase in the number of women detected with CIN III (Table 3 ) is neutralised by a decrease in radical hysterectomies caused by the fall in the number of women diagnosed with cervical cancer stage IB or higher. The number of primary radiotherapies falls as a result of the decrease in the number of diagnosed stages IB and higher.

Tables 3 and 4 can be used to calculate the balance between the efforts and risks needed to prevent more deaths from cervical cancers by more intensive screening. With 5 invitations, for every death avoided, 2800 preventive Pap-smears, 9 referrals and 4 minor treatment procedures are needed. With 25 invitations, the corresponding figures are 7300,22 and 8 .

One reason for the deteriorating balance between beneficial and adverse effects is the strongly increased detection of women with no abnormalities or with lesions which are less advanced than CIN III (Table 3). The second reason is the increased detection of women with CIN III that would have regressed spontaneously. According to our predictions, this number would go from 32 to 77 to 121 per million women per year when

Table 5. More aggressive treatment schedule in CIN and microinvasive cervical cancer (percentages of primary treatment procedures by stage)

\begin{tabular}{lccc}
\hline Treatment & $<$ CIN III* & CIN III & IA \\
\hline None (absence of CIN III) & $55 \%$ & - & - \\
Conserving & $10 \%$ & $20 \%$ & - \\
Exconisation & $10 \%$ & $20 \%$ & $5 \%$ \\
$\begin{array}{l}\text { Exconisation } \\
\text { hysterectomy }\end{array}$ & - & - & $45 \%$ \\
Hysterectomy & $25 \%$ & $60 \%$ & $50 \%$ \\
\hline
\end{tabular}

*Women referred to a gynaecology department for cervical cancer assessment, in whom no CIN or inly CIN I/II is found. intensifying the policy from 5 to 10 to 25 invitations, respectively. The resulting additional treatments, a negative side-effect inherent to early detection of cervical cancer, do not result in avoided invasive disease or life-years gained. Adverse effects all increase at last two to three times as fast as the beneficial effects when intensifying the early detection policy (Fig. 1).

Overall the diagnostic and treatment procedures induced by cervical cancer screening precede the mortality reduction by many years. Discounting of effects (when not considering the costs) is disputable. Nevertheless, when all effects are discounted with a rate of $5 \%$, the ratios between unfavourable and favourable effects rise between $160 \%$ and $200 \%$. There is not only a diminishing return for the extra efforts involved in screening women more frequently, but there is also an increasing risk for women to be referred and treated without having the benefit of invasive disease being presented.

\section{More aggressive early treatment}

The results presented are very sensitive to the treatment procedures assumed in pre-invasive and micro-invasive stages, because of the large number of women concerned. Therefore we also made calculations for a more aggressive schedule, with a shift from minor treatment procedures to hysterectomies and less untreated women (Table 5). The results (Table 6) should be compared with those of Table 3 . There is a sharp increase in the number of hysterectomies: for a limited early detection policy (5 invitations), a net decrease of 2 hysterectomies has now turned into a net increase of 48 . For more intensive screening policies, this number increases nearly linearly, contrary to the number of deaths avoided. This is an important finding, as intensive policies are often advocated, for instance by the National Cancer Institute [14].

The beneficial effects of screening are unaffected by the new assumptions, as survival is reported to remain excellent when more local treatment procedures are used in CIN and cervical cancer stage IA, provided the right selection criteria are used [15-17]. The numbers and types of treatments without early detection remain unchanged, as no women with pre-invasive or micro-invasive disease are detected by symptoms in our calculations.

\section{DISCUSSION}

Complete data on treatments used in women with CIN I and CIN II are scarce. About $10 \%$ of women with CIN III in British

Table 6. Prospective calculations with more aggressive treatment schedule: effects on quantity of diagnosis and primary treatment resulting from three efficient early detection policies

\begin{tabular}{lrrrr}
\hline & \multicolumn{3}{c}{ No. of invitations* } & $\begin{array}{r}\text { No early } \\
\text { detection }\end{array}$ \\
\cline { 2 - 5 } & 5 & 10 & 25 & \\
\hline Women referred & $+117 \dagger$ & +266 & +598 & 182 \\
Conserving treatments & +20 & +42 & +83 & - \\
Exconisations & +20 & +45 & +86 & - \\
Hysterectomies & +48 & +103 & +204 & 72 \\
Primary radiotherapies & -19 & -26 & -35 & 104 \\
Total treatments & +71 & +164 & +338 & 175 \\
\hline
\end{tabular}

*Per woman during her life-time.

$\dagger$ Per year per million women, difference compared with no screening. 
clinics [19-21] have total hysterectomies, and $60-70 \%$ have conserving treatment and $20-30 \%$ have exconisations. This is the opposite of that indicated by Dutch data. The possibility of a quality-bias in the British data cannot be ruled out. But if the average treatment schedule was as suggested by the British data, the numbers of conserving treatments and exconisations in Table 3 should be interchanged. The total level of adverse effects would be lower, but the pattern of increasing risks for women with increasingly intensive policies would remain unchanged.

Results have been calculated for an average duration of preclinical disease of 17 years, a regression rate of $60 \%$ and a sensitivity of $70 \%$. The calculations have been repeated for other values for duration, regression and sensitivity, which could still explain the results of screening in Canada and the Netherlands. The results were not affected substantially. In a sensitivity analysis we also studied the influence of possible changes in incidence and natural history on our results. In case of a higher cervical cancer incidence (in the absence of screening) in the future, all beneficial effects and some adverse effects increase proportionally. A smaller (or larger) number of spontaneously regressing lesions makes adverse effects decrease (or increase), leaving the number of deaths avoided unaltered.

In efficient policies screening starts at about age 30 . It is often advocated to start screening younger, perhaps around age 20 $[14,18]$. Indeed, present screening by general practitioners and gynaecologists concentrates between the ages 20 and 35 . Our calculations indicate that such early detection policies lead to many more diagnostic and treatment procedures per death avoided. For instance a screening policy that invites women every year between the age of 20 and 35, and every 5 years between 35 and 60 [18] has the following cffects. Per death avoided, 11800 smears, 37 referrals and 16 minor treatment procedures are needed. The number of deaths avoided, however, is only 17 per million women per screening year. We found that the ratio between beneficial and adverse effects is dramatically unfavourable compared with those from efficient policies. This is mainly caused by the regression rate of CIN III being especially high in young women and, if screening starts from age 30 or 35 , most of the women with progressive CIN III at early age still detected in this pre-invasive stage, the mean duration of progressive CIN III being about 15 years.

Our predicitions were made for the situation in which followup is advised only after a smear with at least a cytologically moderate dysplasia. Colposcopy after smears with mild dysplasia (or even less severe abnormalities) is also advocated. For quantification of the effects of such a strategy, too little is known about the incidence, regression rate and duration of CIN I and CIN II, and about the sensitivity of the Pap-smear for these abnormalities. Furthermore it is uncertain which protocols for treatment will be used in the future, and how medical practice will be. But the number of referrals and diagnostic and conserving treatment procedures per radical treatment or death avoided will undoubtedly increase. The reasons for this are a relative increase in the number of false positive results (the predictive value will be lower) and the larger number of treated women with regressive lesions, making the plausible assumption that regression is also possible from CIN I and CIN II.

Because we deal with symptom-free women, there is a close relation between balancing risks and benefits in individual women, and decision-making in health care. What counts in both views is an acceptable ratio between beneficial and adverse effects of early detection of cervical cancer. The question is how many referrals for diagnosis, conserving treatment procedures, exconisations and total hysterectomies are acceptable per radical treatment or death avoided. Our aim was not to provide an absolute answer to this question, but to provide the material required to compare different policies on these criteria.

1. Eddy DM. Screening for Cancer: Theory, Analysis and Design. Englewood Cliffs, NJ, Prentice Hall, 1980.

2. Luce BR. The implications of cost-effectiveness analysis of medical technology. An application to cervical cancer screening. Washington, Office Technology Assessment (OTA) Congress 1981.

3. Parkin MD, Moss SM. An evaluation of screening policies for cervical cancer in England and Wales using a simulation model. $f$ Epidemiol Community Health 1986, 40, 143-153.

4. Habbema JDF, van Oortmarssen GJ, Lubbe JThN, van der Maas PJ. Model building on the basis of Dutch cervical cancer screening data. Maturitas 1985, 7, 11-20.

5. Koopmanschap $M$, Lubbe JThN, van Oortmarssen GJ, et al. Economic aspects of cervical cancer screening. Soc Sci Med 1990, 30, 1081-1087.

6. Habbema JDF, Lubbe JThN, van Agt HME, van Ballegooijen $M$, Koopmanschap MA, van Oortmarssen GJ. Costs and Effects of Mass Screening on Cervical Cancer (in Dutch). Rotterdam, Erasmus University, 1988.

7. Boyes DA, Morrison B, Knox EG, Draper GJ, Miller AB. A cohort study of cervical cancer screening in British Columbia. Clin Invest Med 1982, 5, 1-29.

8. Evaluation Commission Cervical Cancer Screening (EVAC). Final Report of the Evaluation Commission Concerning the Early Detection of Cervical Cancer (in Dutch). Rijswijk, Department of Public Health 1988.

9. Information Center for Health Care (SIG). Hospital Diagnosis Statistics $1963-1985$ (in Dutch).

10. Kwikkel HJ. Diagnosis and treatment of cervical intraepithelial neoplasia (CIN) [Dissertation]. Amsterdam, Vrije Universiteit of Amsterdam 1985, 177 pp.

11. Ketting BW. Surgical treatment of invasive carcinoma of the uterine cervix [Dissertation]. Amsterdam, University of Amsterdam, 1981, $175 \mathrm{pp}$.

12. Timmer PR. The treatment of cervical cancer in the Academic Hospital of Groningen from 1970 to 1979 [Dissertation]. Groningen, University of Groningen, $1982,187 \mathrm{pp}$.

13. Evaluation Commission Cervical Cancer Screening (EVAC). Registration of Ceroical Cancer in the Pilot Regions Nijmegen, Rotterdam and Utrecht (in Dutch). Rijswijk, Government Department of Public Health, 1986.

14. Working guidelines for early cancer detection. National Cancer Institute. Int Cancer News 1988, 11.

15. Richart RM, Townsend DE, Crisp W, DePetrello A. An analysis of long-term follow-up results in patients with cervical intraepithelial neoplasia treated by cryotherapy. Am $\mathcal{F}$ Obstet Gynecol 1980, 137, 823-826.

16. Evans AS, Monaghan JM. The treatment of cervical intraepithelial neoplasia using carbon dioxide laser. Br 7 Obstet Gynaecol 1983, 90, 553-556.

17. Jordan JA, Woodman CBJ, Mylotte MJ, Emens JM, Williams DR, Macalary $M$. The treatment of cervical intraepithelial neoplasia by laser vaporization. Br f Obstet Gynaecol 1985, 92, 394-398.

18. Cervical cancer screening programs: summary of the 1982 Canadian Task Force report. Can Med Assoc $\mathcal{7}$ 1982, 127, 581.

19. Pill CF, Letchworth AT, Noble AD. Effect of introduction of colposcopy into a district general hospital. Postgrad Med 3 1984, $60,461-463$.

20. Singer A, Walker P, Tay SK, Dyson J. Impact of introduction of colposcopy to a district general hospital. Br Med J 1981, 289, 1049-1051.

21. Giles JA, Walker PG, Chalk PAF. Treatment of cervical intraepithelial neoplasia (CIN) by radical electrocoagulation diathermy: 5 years experience. BrF Obstet Gynaecol 1987, 94, 1089-1093.

Acknowledgement-This study was financed by the Prevention Fund. 